\title{
The Use of Apps to Prime Learning for a Verbal Task
}

\author{
Christina Frederick, Devin Liskey, Daniel Brown \\ Human Factors and Systems, Embry-Riddle Aeronautical University, Daytona Beach, USA \\ Email: Frederic@erau.edu, LiskeyD@my.erau.edu, BrownD39@my.erau.edu
}

Received 4 September 2013; revised 10 October 2013; accepted 18 October 2013

Copyright (c) 2014 Christina Frederick et al. This is an open access article distributed under the Creative Commons Attribution License, which permits unrestricted use, distribution, and reproduction in any medium, provided the original work is properly cited. In accordance of the Creative Commons Attribution License all Copyrights (C) 2014 are reserved for SCIRP and the owner of the intellectual property Christina Frederick et al. All Copyright $(2014$ are guarded by law and by SCIRP as a guardian.

\section{Abstract \\ This study tested whether or not children's memory performance would be affected by stimulat- ing brain activity by completing a verbal puzzle task or a non-verbal puzzle task prior to a verbal learning task.}

Keywords

Memory; Priming; Learning; Verbal-Learning

\section{Introduction}

Video games and computer games are central forms of entertainment in most children's lives. Numerous studies have shown that children are investing more time in games now than ever in the past. The Kaiser Family Foundation has tracked media use of 8 to 18-year-olds from 1999 to 2009 and has found that in a single decade, daily computer and video game use has tripled from a single hour to three. During a seven-day week, the average child was engaged in computer and video games for 19 hours, nearly two thirds of the time spent in classroom [1]. The NPD Group, a market information and advisory service, in their 2011 report of Kids and Gaming, found that between 2009 and 2011 the US population under 18 grew by 1.5\% while the gaming population of the same demographic grew by $12.68 \%$, encompassing $91 \%$ of kids today [2]. While virtual gaming has typically been viewed as a distraction that causes students to neglect either their schooling and/or homework, researchers and educators are investigating the role of virtual games in supporting children's learning inside and out of school. A study out of the Educational Psychology Program at the University of New Mexico found that interactive multimedia may promote learning better than traditional methods. Presenting students with dual re- 
presentations of information, verbal and non-verbal, promotes deeper learning presenting students with only one representation. Interactive multimedia also has the ability to vary the number of representations, degree of interactivity, and tailor the difficulty to each individual [3].

The purpose of this study is to determine if stimulating brain activity using iPad game apps prior to a verbal learning task would facilitate memory performance. Furthermore, we tested whether or not memory performance would be affected if children completed a verbal puzzle task (word search) in comparison to completing a non-verbal puzzle task ("flow" puzzle) prior to a verbal learning task. Performance in these two puzzle groups was compared to a control group that did not engage in puzzle solving before the learning task. The iPad games in pre-task were chosen to match (verbal) or have dissimilar (non-verbal) brain activation as the subsequent verbal learning task. Different sources of stimulus-based priming can interfere with, rather than facilitate activation of the correct task [4]. The correct task in this case would be the verbal learning task. The activation of words in pre-task and their recovery in the subsequent test is referred to as priming [5]. The initial task, or the stimulus-based prime, is thought to leave a persisting activation in the corresponding effected areas of the brain. The verbal learning puzzle activates the left frontal cortex, and the left hemispheric areas of the brain associated with verbal learning areas in the left temporal and parietal lobes [6]. The non-verbal puzzle stimulates the right frontal cortex of the brain, which is not specifically associated with verbal learning, but is associated with planning and executive control [7]. This type of non-verbal puzzle has been used to try to enhance learning in students who may have difficulty with verbal learning, such as those with dyslexia [8]. Both puzzle tasks involve visual scanning and search and thus also engage the occipital or visual lobe of the brain [9].

\section{Method}

\subsection{Priming}

Participating children, 3rd graders from a public charter school in Florida, were divided into three groups. Each participant group consisted of between 9 and 11 students randomly assigned to the groups by their teachers. The first group was asked to play a word search, app-based puzzle for 10 minutes. The word search consisted of a grid with words written horizontally, vertically, and diagonally, which were obscured among random letters. Players are meant to find all the hidden words within the grid. The second group was asked to play a non-verbal puzzle game for 10 minutes. The non-verbal puzzle was an iPad app called "Flow Free", where the player has to connect pairs of dots of the same color in a grid while not allowing any of the paths of each color to overlap. The control group was provided with ten minutes of free time in their seats. Each experimental group was asked to make as much progress with their game as possible.

\subsection{Written Test}

At the end of the ten minutes, the iPads were collected and a single page story on the history of Embry-Riddle Aeronautical University was distributed. Students were told to follow along as the story was read aloud by a researcher. Once the story was read, the handouts were collected and a test on the story was distributed. There was no time restriction on the completion of the test. It was hypothesized that the group that was primed before learning with a verbal puzzle would perform better on a subsequent verbal learning task than either the nonverbal puzzle group or the control group.

The tests were analyzed for the: 1 ) number of correctly "recalled" items-items from the test where the student had to remember and report a specific date or number 2) number of correctly "recognized" items (e.g. items where the student had to choose the correct answer from a number of alternatives) and 3) self-reported perceptions of how enjoyable the task was, how well the student felt he/she could remember the information and how well the student felt he/she could attend to the task.

\section{Results}

A multivariate analysis of variance (MANOVA) was conducted to measure the effectiveness of the verbal and non-verbal puzzle primes on the graded verbal task. The independent measure was the type of learning prime received which was divided into three groups: word search, flow-free, and control. Each student's ability to recall or recognize the correct answer on multiple choice questions as well as their individual perceptions of task 
enjoyment, memory ability and ability to attend to the task were dependent measures. A second MANOVA was performed on a second test administered two weeks later on the same students to examine retention effects. The mean scores for each section for both tests are listed in Tables 1 and 2 below. Before conducting each MANOVA, the data were screened for completeness. Several individuals' data were unable to be included in the analysis because their school attendance did not allow them to complete both tests.

Using the Wilk's criterion at an alpha level of .05, the dependent variables of recall, recognition, and individual perceptions were not significantly affected by either the verbal or non-verbal puzzle primes in the initial test, $\beta=0.379, F(10,45)=0.836, p=0.597$ with an effect size of 0.148 . The post-test analysis found significant differences amongst the scores with $\beta=0.985, F(4,54)=6.455, p<0.001$ and effect size of 0.323 . A univariate F-test found no group differences in post-test recall or on any of the individual perception variables, but revealed a significant difference in post-test recognition, $F(2,31)=15.523, p<0.001$. Tukey's HSD was applied and showed that the Flow-Free group differed significantly from both the control group and the group primed with the word search. The Free Flow group scored about $80 \%$ lower than the other two groups. These results are presented in Table 3.

Our hypothesis that the group primed with the word search puzzle would outperform the other two groups was only partially supported by the data as there was not a statistically significant difference in overall score, recall, or recognition between the groups in the initial test, but the word search group did perform significantly higher than the non-verbal puzzle group on post-test recognition. It can be noted however, the standard deviation of overall memory performance in initial testing for the word search group ( $\mathrm{SD}=1.84$ ) was much smaller than that of the control $(\mathrm{SD}=3.04)$ and non-verbal puzzle group $(\mathrm{SD}=2.71)$.

\begin{tabular}{ccccc|}
\hline \multirow{2}{*}{ Table 1. Initial test results. } \\
\hline \multirow{5}{*}{ Measures } & \multicolumn{4}{c|}{ Initial test results } \\
\cline { 2 - 5 } & Overall score & Free flow group & Word search & Control group \\
\hline Total performance & $5.4 / 12$ & 5.4 & 4.9 & 5.8 \\
Recall & $2.6 / 8$ & 2.9 & 1.9 & 2.9 \\
Recognition & $2.8 / 4$ & 2.5 & 3 & 2.9 \\
Fun & $4.8 / 5$ & 4.8 & 4.6 & 4.9 \\
Remember & $3.7 / 5$ & 3.6 & 3.5 & 4.2 \\
Attention & $4.5 / 5$ & 4.6 & 4.4 & 4.7 \\
\hline
\end{tabular}

Table 2. Post-test results.

\begin{tabular}{ccccc}
\hline \multirow{2}{*}{ Measures } & \multicolumn{4}{c}{ Post-test results } \\
\cline { 2 - 5 } & Overall & Free flow group & Word search & Control \\
\hline Total performance & $4.7 / 12$ & 4.9 & 4.8 & 4.4 \\
Recall & $2.7 / 8$ & 2.8 & 2.8 & 2.3 \\
Recognition & $1.4 / 4$ & 0.4 & 2 & 2.1 \\
\hline
\end{tabular}

Table 3. Post-test group performance.

\begin{tabular}{|c|c|c|c|c|c|}
\hline \multicolumn{6}{|c|}{ Post hoc means table } \\
\hline \multirow{2}{*}{$\begin{array}{c}\text { Dependent } \\
\text { variable }\end{array}$} & \multirow{2}{*}{ Group } & \multirow{2}{*}{ Mean } & \multirow{2}{*}{ Std. Error } & \multicolumn{2}{|c|}{ 95\% confidence interval } \\
\hline & & & & Lower bound & Upper bound \\
\hline \multirow{3}{*}{$\begin{array}{l}\text { Post-test } \\
\text { recognition }\end{array}$} & Control & 2.111 & 0.266 & 1.567 & 2.656 \\
\hline & Flow & 0.417 & 0.230 & -0.055 & 0.888 \\
\hline & Word Search & 2.000 & 0.252 & 1.483 & 2.517 \\
\hline
\end{tabular}




\section{Conclusion}

There are several possible reasons why statistically significant learning differences between the groups were not found during initial testing. First, the sample of $\mathrm{N}=33$ students, was only half of what was required to reach $\beta=$ 0.4 with a $\eta=0.25$. If more participants were involved in the study perhaps a greater distinction between the groups could be seen. A significant difference between the two primed groups and the control group may have been apparent with a larger sample and more testing. It's also possible that a distinction between these two groups may not have been seen in part because the stimulus-based primes did not affect the brain in significantly different ways. Non-verbal activities like the one used in this study have been used in past studies to help students suffering with learning disabilities such as dyslexia to enhance their verbal skills. Students with this learning disposition have been shown to learn more effectively when presented with spatial and non-verbal information rather than verbal sources [10]. The non-verbal prime may have actually benefitted the students instead of creating task interference as intended. Interference of this kind only manifests itself in performance when there is a high level of competition between the stimulus based-prime and the subsequent task [4]. Even the fact that the students followed along in reading while an instructor read text aloud may have been enough to boost the performance of the students on the test. Reading silently and in their heads would have stimulated Broca's area in brain, which is associated with inner speech and verbal learning. The students may have received an unintentional prime for verbal learning that blurred the intentional disparity created by the verbal and non-verbal puzzles [11]. Third, the closely distributed results could be due to the Hawthorne Effect. The Hawthorne Effect describes the awareness of the participant of the presence of something new in the environment and this changes the participant's behavior [12]. The novelty associated with the presence of the experimenters and iPads may have been enough to stimulate the students in all three groups enough to increase their focus and attention to the level the stimulation from their respective primes would have otherwise provided. Lastly, it could be that the primes for learning were either ineffective or that they were not of long enough duration to produce an effect. Over the next couple months, our research team will be examining the results of this study in more detail to determine which of these explanations is most likely and further research will proceed from those conclusions.

\section{References}

[1] Rideout, V., Foehr, U. and Roberts, D. (2010) Generation M2 media in the lives of 8- to 18-year-olds. Kaiser Family Foundation, Menlo Park.

[2] NPD Group (2011) The video game industry is adding 2-17 year-old gamers at a rate higher than that age group's population growth [press release]. https://www.npd.com/wps/portal/npd/us/news/press-releases/pr 111011/

[3] Moreno, R. and Valdez, A. (2005) Cognitive load and learning effects of having students organize pictures and words in multimedia environments: The role of student interactivity and feedback. Educational Technology Research and Development, 53, 35-45.

http://www.etc.edu.cn/Cognitive_Load_and_Learning_Effects_of_Having_Students_Organize_Pictures_and_Words_i n_Multimedia_Environments.pdf http://dx.doi.org/10.1007/BF02504796

[4] Koch, I. and Allport, A. (2006) Cue-based preparation and stimulus-based priming of tasks in task switching. Memory \& Cognition, 34, 433-444. http://link.springer.com/article/10.3758\%2FBF03193420 http://dx.doi.org/10.3758/BF03193420

[5] Segal, S. (1967) The priming of association test responses: Generalizing the phenomenon. Journal of Verbal Learning and Verbal Behavior, 6, 216-221. http://dx.doi.org/10.1016/S0022-5371(67)80099-9

[6] Crank, M. and Fox, P. (2002) Broca's Area. In Encyclopedia of the Human Brain, 569-586.

[7] Kemenoff, L., Miller, B. and Kramer, J. (2002) Frontal Lobe. In Encyclopedia of the Human Brain, 317-325.

[8] Winn, W., Berninger, V., Richards, T., Aylward, E., Stock, P., Lee, Y. and Lovitt, D. (2006) Effects of nonverbal problem solving treatment on skills for externalizing visual representation in upper elementary grade students with and without dyslexia. Journal of Educational Computing Research, 34, 381-404. http://eric.ed.gov/?id=EJ757163 http://dx.doi.org/10.2190/R783-4G36-58V7-5154

[9] Deyoe, E. (2002) Occipital lobe. In Encyclopedia of the Human Brain, 677-715.

[10] Levin, J.R., Anglin, G.J. and Carney, R.N. (1987) On empirically validating functions of pictures in prose. In: Willows, D.M. and Houghton, H.A., Eds., The Psychology of Illustration: Basic Research, Springer, New York, 51-85. 
http://dx.doi.org/10.1007/978-1-4612-4674-9_2

[11] Tuller, B., Jantzen, K., Olvera, D., Steinberg, F. and Kelso, J. (2007) The influence of instruction modality on brain activation in teenagers with nonverbal learning disabilities: Two case histories. Journal of Learning Disabilities, 40, 348-359. http://dx.doi.org/10.1177/00222194070400040501

[12] Olson, R., Verley, J., Santos, L. and Salas, C. (2004) What we teach students about the hawthorne studies: A review of content within a sample of introductory IO and OB textbooks. The Industrial-Organizational Psychologist, 41, 23-39. http://www.siop.org/TIP/backissues/Jan\%2004/pdf/413_023to039.pdf 